\title{
Human Epididymis Protein-4 Gene Expression as a Biomarker in Patients with Ovarian Cancer in Iran
}

\author{
Arezo Shahi' ${ }^{1}$ Naghmeh Bahrami ${ }^{2}$, Atefeh Fakharian ${ }^{3,4}$, Somayeh Sharifynia ${ }^{5}$, Elham Moslemi ${ }^{*}$, \\ Amir Izadi ${ }^{7,8}$, Adnan Khosravi', Hamidreza Jamaati ${ }^{3,4}$, Abdolreza Mohamadnia10,11
}

\author{
${ }^{1}$ Department of Biology, Faculty of Basic Sciences, Islamic Azad University, North Tehran Branch, Tehran, Iran \\ ${ }^{2}$ Craniomaxillofacial Research center, Tehran University of Medical Sciences, Tehran, Iran \\ Oral and Maxillofacial Surgery Department, School of Dentistry, Tehran University of Medical Sciences, Tehran, Iran \\ ${ }^{3}$ Chronic Respiratory Diseases Research Center, National Research Institute of Tuberculosis and Lung Diseases (NRITLD), Shahid \\ ${ }^{4}$ Beheshti University of Medical Sciences, Tehran, Iran \\ ${ }^{5}$ Clinical Tuberculosis and Epidemiology Research Center, National Research Institute of Tuberculosis and Lung Diseases \\ (NRITLD), Shahid Beheshti University of Medical Sciences, Tehran, Iran \\ ${ }^{6}$ Department of Biology, Islamic Azad University, Tehran East, Tehran, Iran \\ ${ }^{7}$ Young Researchers and Scholars Club, Islamic Azad University, Tehran East, Tehran, Iran \\ ${ }^{8}$ Bunge Oxir Research Institute, Iran \\ ${ }^{9}$ Tobacco Prevention and Control Research Center, National Research Institute of Tuberculosis and Lung Diseases (NRITLD), \\ Shahid Beheshti University of Medical Sciences, Tehran, Iran \\ ${ }^{10}$ Virology Research Center, National Research Institute of Tuberculosis and Lung Diseases (NRITLD), Shahid Beheshti University \\ of Medical Sciences, Tehran, Iran \\ ${ }^{11}$ Department of Biotechnology, School of Advanced Technologies in Medicine, Shahid Beheshti University of Medical Sciences, \\ Tehran, Iran \\ Email: *Elham_moslemi60@yahoo.com
}

How to cite this paper: Shahi, A., Bahrami, N., Fakharian, A., Sharifynia, S., Moslemi, E., Izadi, A., Khosravi, A., Jamaati, H. and Mohamadnia, A. (2017) Human Epididymis Protein-4 Gene Expression as a Biomarker in Patients with Ovarian Cancer in Iran. Open Journal of Clinical Diagnostics, 7, 83-90.

https://doi.org/10.4236/ojcd.2017.73009

Received: March 2, 2017

Accepted: August 11, 2017

Published: August 14, 2017

Copyright $\odot 2017$ by authors and Scientific Research Publishing Inc. This work is licensed under the Creative Commons Attribution International License (CC BY 4.0).

\begin{abstract}
Introduction: Ovarian cancer is one of the most common malignancies in women and the fifth cause of cancer-related deaths in women worldwide. Contrary to the challenges in developing new clinical markers using the conventional methods, recent advances in genomics and proteomics have led to identification of candidate and promising biomarkers for the diagnosis of ovarian cancer. Human epididymis protein 4 (HE4) is such a marker that has recently been reported to correlate with recurrence or progression of epithelial ovarian cancer. The purpose of this study was to measure the expression level of HE4 gene in women with ovarian cancer. Methodology: We evaluated and compared paraffin-embedded tissue samples of 20 ovarian cancer patients with 10 samples from healthy individuals. RNA was initially extracted from the samples and cDNA was synthetized. Gene expression level was then measured using real-time polymerase chain reaction (PCR). Results: Our results demonstrated that HE4 gene expression level was significantly higher in
\end{abstract}


http://creativecommons.org/licenses/by/4.0/

Open Access samples of patients with ovarian cancer compared with samples from healthy individuals. Moreover, higher levels of HE4 gene expression were associated with more advanced disease and larger tumor size. Conclusion: HE4 gene over-expression has the potential to be used as a biomarker for detecting earlystage ovarian cancer in women. Future more comprehensive studies are needed to confirm our findings.

\section{Keywords}

Ovarian Neoplasms, Genomics, Tumor Biomarkers, HE4 Protein

\section{Introduction}

Ovarian cancer is among the most challenging fatal cancers in women, as it is usually silent in its early stages with no or little signs and symptoms. Inability to make an early diagnosis through screening or other methods results in a late presentation at an advanced stage [1]. Although the lifetime risk of ovarian cancer in a woman is equal to $1.5 \%$ and it constitutes only about $4 \%$ of all cancers in females, it is the fifth leading cause of cancer deaths in this population with a high mortality rate of up to $70 \%$ [2]. Therefore, early detection of the disease is of utmost importance and significantly affects the survival of patients [3] [4]. There is an inverse relationship between the number of pregnancies and the incidence of ovarian cancer, and a direct one is present regarding infertility. In addition, early puberty and late menopause increase this risk as well [5]. This implies that suppression of ovulation may be an important factor in prevention of ovarian cancer, since the surface epithelium of ovaries experiences frequent damage and healings, which could lead to emergence of spontaneous mutations and oncogenic phenotypes [6].

Despite the importance of early disease detection, an ideal screening test with high sensitivity and specificity has not yet been developed for ovarian cancer. Current screening methods including physical examination, cancer antigen 125 (CA-125), and vaginal ultrasound are successful in identifying the disease only in 30 to $45 \%$ of women with ovarian cancer. Tumor markers are another method for early detection or monitoring of the disease and are widely used today [7] [8]. Human epididymis protein 4 (HE4) is a recently identified biomarker, with a molecular weight of about $25 \mathrm{kDa}$ encoded by WAP four-disulfide core domain 2 (WFDC2) gene located on chromosome q1213.120. WFDC2 gene has shown high amplification rates in ovarian cancer; whereas, its expression is low in healthy ovarian tissue. The highest expression of this gene is in normal respiratory and glandular epithelial tissues.

The amount of HE4 mRNA increases in different types of ovarian cancer, and it can be detected in the serum by enzyme-linked immunosorbent assay (ELISA), yielding a higher sensitivity and specificity than CA-125 for diagnosing malignancy. It has $95 \%$ sensitivity and $72.9 \%$ specificity for detection of ovarian cancer. 
Measuring HE4 levels in urine can also be used for the diagnosis and follow-up of ovarian cancer [9] [10]. Moreover, HE4 gene expression varies in different ovarian cancers and may help differentiate the subtypes; it shows a $100 \%$ rise in the endometrioid type, versus a $93 \%$ rise in serous ovarian tumors [10].

We thus aimed to investigate HE4 gene expression in our ovarian cancer patients and evaluate its correlation with disease stage, to be able to provide recommendations for the use of this relatively new tumor marker in our country.

\section{Materials and Methods}

\subsection{Specimen Collection and Preparation}

We selected 20 samples from our patients with ovarian cancer and 10 samples from healthy individuals. Ten-micron slides were prepared from each paraffin block and reviewed by a pathologist.

\subsection{RNA Extraction}

RNA was extracted using di-paraffin xylene followed by xylene and ethanol. Samples were then treated with proteinase $\mathrm{k}$ and the buffer of RNA was handled using standard protocols and RNX Plus solution [11]. After extraction, RNA quality was assessed by spectrophotometry, which showed an optical density of $280 / 260 \mathrm{~nm}$.

\section{3. cDNA Synthesis from RNA}

Ten $\mu \mathrm{L}$ of RNA template was mixed with $1 \mu \mathrm{L}$ of $10 \mathrm{Mm}$ deoxynucleotide (dNTP) and $1 \mu \mathrm{L}$ of Random Hexamer, followed by $1 \mu \mathrm{L}$ of Oligo dT in a stepwise fashion. Tubes were then placed at $65^{\circ} \mathrm{C}$ for 5 minutes. Next, $2 \mu \mathrm{L}$ of M-MuLV $10 \times$ buffer and $0.5 \mu \mathrm{L}$ of M-MuLV enzyme were added to the mixture, and water was used to reach the volume to $20 \mu \mathrm{L}$. Finally, the tubes were incubated at $42^{\circ} \mathrm{C}$ for one hour.

\subsection{Designing Specific Primers for Glyceraldehyde 3-Phosphate Dehydrogenase (GAPDH) and HE4 Genes}

Unique primers of each gene were designed by AlleleID7 software and produced. Primer sequences were compared to the National Center for Biotechnology Information (NCBI) database and rechecked with Gene Runner, in order to ensure their accuracy. Our primer sequences are presented in Table 1.

Table 1. Sequence of primers used in our study.

\begin{tabular}{ccc}
\hline Name & Primer sequence & Amplicon Size \\
\hline HE4-F & GTGTCCTGTGTCACTCCCAA & $62 \mathrm{bp}$ \\
HE4-R & CTCTCCTCACTGCTCAGCCT & \\
GAPDH-F & CCCACACACATGCACTTACC & $85 \mathrm{bp}$ \\
GAPDH-R & TGCCTGTCCTTCCTAGCTCT & \\
\hline
\end{tabular}




\subsection{Optimizing Basic Factors of Real Time-Polymerase Chain Reaction (PCR) for GAPDH and HE4 Genes}

For this purpose, ABI7500 device was used to prepare a separate response for target and internal control genes in a final volume of $20 \mu \mathrm{L}$. Reactions were placed in parallel on the device. In each reaction, $10 \mu \mathrm{M}$ SYBR TM (2X) ${ }^{\circ}$ Premix and $10 \mu \mathrm{M}$ of reverse and forward Primers as well as cDNA templates were used in concentrations of $2 \mu \mathrm{g}$.

Forty full cycles were performed at a reaction temperature of $95^{\circ} \mathrm{C}$ for 15 seconds, followed by $60^{\circ} \mathrm{C}$ for one minute. In order to confirm the amplified fragment and ensure the absence of non-specific product, primer dimer, and pollution, segregation curve analysis was performed. After optimization test, RNAs of all samples were extracted and their quality was confirmed. cDNAs were then synthetized. After the reaction, raw data were extracted and subjected to double-delta $\mathrm{Ct}(\Delta \Delta \mathrm{Ct})$ method. Expression rates were calculated and read from the device according to relative quantification (RQ), or alternatively, were converted and measured using $\Delta \Delta \mathrm{Ct}$ method [12]-[17]. The expression levels of all samples of tumoral tissue were compared with the average RQ of normal samples calculated by the device. Gene expression graphs were drawn using the Graph pad software.

\section{Results}

We evaluated 20 samples from ovarian cancer and 10 from healthy individuals. There was no difference in the mean age of the patients from whom the samples were taken $(P$ value $=0.652)$.

The expression of patient samples in comparison with the normal sample stated that the obtained results than the expression of the gene in tissue is normal.

Our results showed that the expression of HE4 gene in ovarian cancer patients had an approximately 4-time increase compared to the normal tissue (Figure 1). This increased expression was seen in all ovarian cancer samples. Moreover, the highest expression rates were observed in the samples obtained from patients with stage-III disease (samples 1, 2, 12, and 15), followed by those of patients with stage-II (samples 5, 13, 14). The lowest expression rate was seen in the sample of a patient with stage-I disease (sample 4), which was still higher than the normal HE4 gene expression.

When comparing the samples, it was found that the average HE4 gene expression level was significantly higher in samples of patients with stage-I, stage-II, and stage-III/IV than in normal ovarian tissue $(3.374,3.701$, and 4.0335 vs. 1 , respectively, $P<0.001$ for all comparisons, Figure 2), which also signified higher expression levels in more advanced stages of the disease.

In addition, comparing the average HE4 gene expression levels in patients younger than 50 years with those older than 50 showed that expression level was higher in younger patients: 4.135 vs. 4.032 , respectively. When we analyzed the 


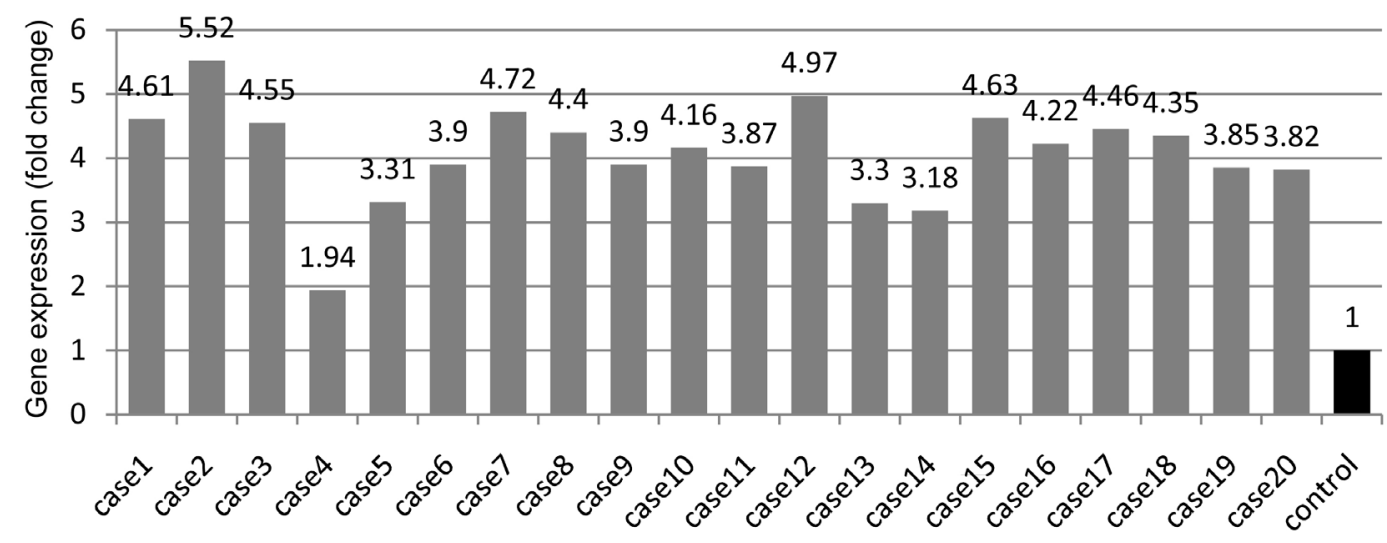

Figure 1. HE4 gene expression levels in patients with ovarian cancer compared to normal controls.

\section{average HE4 gene expression}

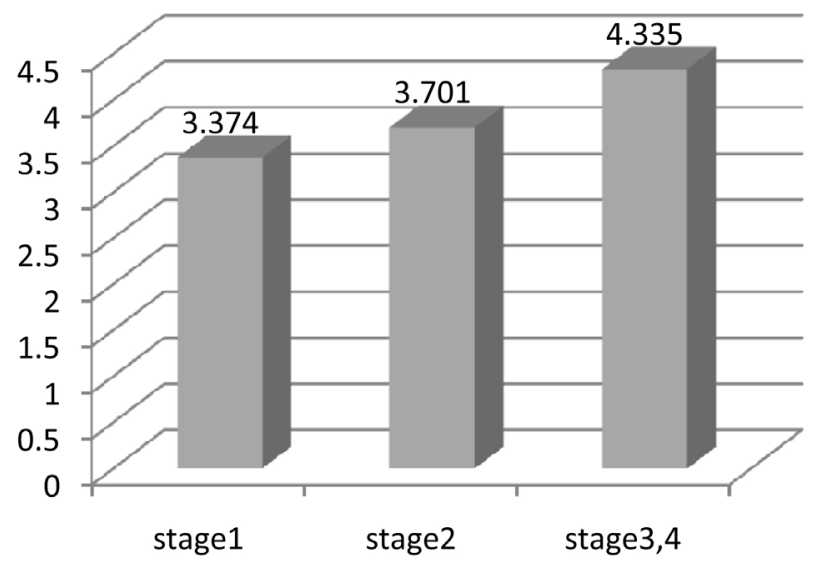

average HE4 gene expression

Figure 2. HE4 gene expression levels in different stages of ovarian cancer.

expression levels with respect to tumor size, we found that larger tumors had a higher expression level.

\section{Discussion}

Diagnosis of ovarian cancer at an early stage enables the clinicians to plan an effective treatment; hence a better prognosis can be achieved before the spread of the disease [18]. Despite the widespread use of conventional screening tests, ovarian cancer still has a high mortality rate [19]. More than $80 \%$ of the cases are diagnosed at an advanced stage, leading to a low $10 \%-20 \%$ survival rate [20].

Regarding the pathophysiology of the disease, reproductive hormones are thought to play a major role. Fathalla in 1971 suggested that a relationship is present between repeated ovulations and the formation of malignant tumors on the surface of the ovaries [21].

In a study by Fleming et al, CA-125 and pelvic ultrasound were used for diagnosis of ovarian cancer. In as high as $20 \%$ of ovarian cancer patients, CA-125 could not detect the disease; besides, since it is a nonspecific biomarker, it shows 
elevations in other gynecological pathologies as well. Sensitivity and specificity of CA-125 for detection of ovarian cancer are not favorable either [21]. This has led to efforts to improve diagnostic accuracy by investigating new biomarkers or using a combination of them such as mesothelin, CA74-4, inhibin, kallikreins, and osteopontin alongside CA-125.

Human epididymis protein 4, a WAP four-disulfide core domain 2 protein, was first identified in the outer cell membrane of distal spermatic cord and was found to act as a repressive protease involved in sperm maturation. Multiple studies have also demonstrated its presence in the normal ovary and uterine, as well as in neoplasms of these two organs [10] [22], which synthetize this protein in higher amounts, especially the serous and endometrial subtypes. Two monoclonal antibody derivatives used for its measurement by ELISA include $52 \mathrm{H}$ and 83D epitopes, particularly in postmenopausal women [23]. It is now accepted as a newly developed biomarker with higher sensitivity and specificity [24].

In a recent study, HE4 had the highest sensitivity in detecting early stages of ovarian cancer, when used separately or in combination with CA-125 [24]. Moreover, in a 2003 article published in the Journal of Cancer Research, HE4 was compared to CA-125 for the ability to differentiate ovarian pathologies in 37 ovarian cancer patients, 19 patients with benign ovarian disease, and 65 healthy individuals. The authors concluded that HE4 and CA125 have comparable sensitivity and specificity, while HE4 was superior to CA-125 in early detection of ovarian cancer [22]. Another study reported $76.5 \%$ sensitivity and $95 \%$ specificity for the simultaneous use of HE4 and CA-125 for differentiating benign from malignant lesions [8] [25]. Our results confirmed these findings and showed higher HE4 expression levels in cancer patients compared to normal individuals.

\section{Conclusion}

In conclusion, our results serve as a foundation in support of the use of HE4 as a screening and diagnostic tool for ovarian cancer and its follow-up. This study was the first-of-its-kind in Iran and showed significantly higher expression rates of HE4 gene in cancer patients, which also correlated with tumor stage and size. We also believe real-time PCR is a practical, fast, and accurate method to be used in this regard. Future studies are needed to validate the use of this biomarker in our population.

\section{References}

[1] Lalwani, N., Prasad, S.R., Vikram, R., Shanbhogue, A.K., Huettner, P.C. and Fasih, N. (2011) Histologic, Molecular, and Cytogenetic Features of Ovarian Cancers: Implications for Diagnosis and Treatment. Radiographics, 31, 625-646. https://doi.org/10.1148/rg.313105066

[2] Siegel, R., Naishadham, D. and Jemal, A. (2012) Cancer Statistics, 2012. CA: $A$ Cancer Journal for Clinicians, 62, 10-29. https://doi.org/10.3322/caac.20138

[3] Rauh-Hain, J.A., Krivak, T.C., del Carmen, M.G. and Olawaiye, A.B. (2011) Ovarian Cancer Screening and Early Detection in the General Population. Reviews in Obstetrics and Gynecology, 4, 15. 
[4] Badgwell, D. and Bast Jr., R.C. (2007) Early Detection of Ovarian Cancer. Disease Markers, 23, 397-410. https://doi.org/10.1155/2007/309382

[5] Chen, V.W., Ruiz, B., Killeen, J.L., Coté, T.R., Wu, X.C., Correa, C.N., et al. (2003) Pathology and Classification of Ovarian Tumors. Cancer, 97, 2631-2642.

https://doi.org/10.1002/cncr.11345

[6] Heravi-Moussavi, A., Anglesio, M.S., Cheng, S.-W.G., Senz, J., Yang, W., Prentice, L., et al. (2012) Recurrent Somatic DICER1 Mutations in Nonepithelial Ovarian Cancers. New England Journal of Medicine, 366, 234-242. https://doi.org/10.1056/NEJMoa1102903

[7] Bast Jr., R.C., Klug, T.L., John, E.S., Jenison, E., Niloff, J.M., Lazarus, H., et al. (1983) A Radioimmunoassay Using a Monoclonal Antibody to Monitor the Course of Epithelial Ovarian Cancer. New England Journal of Medicine, 309, 883-887. https://doi.org/10.1056/NEJM198310133091503

[8] Moore, R.G., Brown, A.K., Miller, M.C., Skates, S., Allard, W.J., Verch, T., et al. (2008) The Use of Multiple Novel Tumor Biomarkers for the Detection of Ovarian Carcinoma in Patients with a Pelvic Mass. Gynecologic Oncology, 108, 402-408. https://doi.org/10.1016/j.ygyno.2007.10.017

[9] Rosen, D.G., Wang, L., Atkinson, J.N., Yu, Y., Lu, K.H., Diamandis, E.P., et al. (2005) Potential Markers that Complement Expression of CA125 in Epithelial Ovarian Cancer. Gynecologic Oncology, 99, 267-277. https://doi.org/10.1016/j.ygyno.2005.06.040

[10] Drapkin, R., von Horsten, H.H., Lin, Y., Mok, S.C., Crum, C.P., Welch, W.R., et al. (2005) Human Epididymis Protein 4 (HE4) Is a Secreted Glycoprotein that Is Overexpressed by Serous and Endometrioid Ovarian Carcinomas. Cancer Research, 65, 2162-2169. https://doi.org/10.1158/0008-5472.CAN-04-3924

[11] Izadi, A., Moslemi, E., Poorhosseini, S.M., Yassaee, V.R., Kheiri, H.R. and Elikai, H.R. (2014) UBD Identify in Paraffin Tissues in Patients with Colorectal Cancer. Journal of Isfahan Medical School, 32, 1-10.

[12] Karimi, S., Mohamadnia, A., Nadji, S.A., Yadegarazari, R., Khosravi, A., Bahrami, N., et al. (2015) Expression of Two Basic mRNA Biomarkers in Peripheral Blood of Patients with Non-Small Cell Lung Cancer Detected by Real-Time rt-PCR, Individually and Simultaneously. Iranian Biomedical Journal, 19, 17.

[13] Mohamadnia, A., Karimi, S., Yadegar Azari, R., Naji, S.A., Khosravi, A., Bahrami, N., et al. (2016) Expression of CK19 Gene in Patients with Lung Cancer and Its Comparison with Carcinoembryonic Antigen in Peripheral Blood. Journal of Payavard Salamat, 9, 459-468.

[14] Bahrami, N., Gholami, M., Jamaati, H.R., Mohamadnia, A., Dargahi, H., Kazempour Dizaji, M., Khosravi, A., Heshmatnia, J., Vahabi, P. and Bahrami, N.A. (2016) Expression of Two Essential mRNA Biomarker in the Peripheral Blood as Possible Biomarkers for Diagnosis of Non-Small Cell Lung Carcinoma. Minerva Pneumologica, 55, 31-36.

[15] Jamaati, H., Bahrami, N., Abniki, M., Tabarsi, P., Farzanegan, B., Doroudinia, A., et al. (2016) Real-Time RT-PCR Detection of HCN4 and ADAM8 Genes in Ventilator-Associated Pneumonia Patients Hospitalized in Intensive Care Unit. Journal of Cellular and Molecular Anesthesia, 1, 163-167.

[16] Karimi, S., Bahrami, N., Sharifi, K., Daustany, M., Baghbani-Arani, F., Kazempour, M., et al. (2017) Investigating Gene Expression Level of MUC1 and CEA in Pleural Fluid of NSCLC Lung Cancer Patients with Real-Time RT-PCR Method. Minerva Pneumologica, 56, 18-24. 
[17] Ghadimi, K., Bahrami, N., Fathi, M., Farzanegan, B., Naji, T., Emami, M., et al. (2017) Diagnostic Value of LunX mRNA and CEA mRNA Expression in Pleural Fluid of Patients with Non-Small Cell Lung Cancer. Minerva Pneumologica, 56, 9095.

[18] Bingham, C., Roberts, D. and Hamilton, T. (2001) The Role of Molecular Biology in Understanding Ovarian Cancer Initiation and Progression. International Journal of Gynecological Cancer, 11, 7-11. https://doi.org/10.1046/j.1525-1438.2001.11(suppl.1)sup1007.x

[19] Maclean, A. (2012) Ovarian Tumours, Their Characterisation and Origins and Ovarian Screening. Journal of Obstetrics and Gynaecology, 32, 205-207. https://doi.org/10.3109/01443615.2012.656159

[20] Jemal, A., Siegel, R., Ward, E., Hao, Y., Xu, J. and Thun, M.J. (2009) Cancer Statistics, 2009. CA: A Cancer Journal for Clinicians, 59, 225-249. https://doi.org/10.3322/caac.20006

[21] Fleming, J.S., Beaugié, C.R., Haviv, I., Chenevix-Trench, G. and Tan, O.L. (2006) Incessant Ovulation, Inflammation and Epithelial Ovarian Carcinogenesis: Revisiting Old Hypotheses. Molecular and Cellular Endocrinology, 247, 4-21. https://doi.org/10.1016/j.mce.2005.09.014

[22] Hellström, I., Raycraft, J., Hayden-Ledbetter, M., Ledbetter, J.A., Schummer, M., McIntosh, M., et al. (2003) The HE4 (WFDC2) Protein Is a Biomarker for Ovarian Carcinoma. Cancer Research, 63, 3695-3700.

[23] Anastasi, E., Marchei, G.G., Viggiani, V., Gennarini, G., Frati, L. and Reale, M.G. (2010) HE4: A New Potential Early Biomarker for the Recurrence of Ovarian Cancer. Tumor Biology, 31, 113-119. https://doi.org/10.1007/s13277-009-0015-y

[24] Park, Y., Lee, J.-H., Hong, D.J., Lee, E.Y. and Kim, H.-S. (2011) Diagnostic Performances of HE4 and CA125 for the Detection of Ovarian Cancer from Patients with Various Gynecologic and Non-Gynecologic Diseases. Clinical Biochemistry, 44, 884888. https://doi.org/10.1016/j.clinbiochem.2011.04.011

[25] Moore, R.G., McMeekin, D.S., Brown, A.K., DiSilvestro, P., Miller, M.C., Allard, W.J., et al. (2009) A Novel Multiple Marker Bioassay Utilizing HE4 and CA125 for the Prediction of Ovarian Cancer in Patients with a Pelvic Mass. Gynecologic Oncology, 112, 40-46. https://doi.org/10.1016/j.ygyno.2008.08.031

\section{Submit or recommend next manuscript to SCIRP and we will provide best} service for you:

Accepting pre-submission inquiries through Email, Facebook, LinkedIn, Twitter, etc. A wide selection of journals (inclusive of 9 subjects, more than 200 journals)

Providing 24-hour high-quality service

User-friendly online submission system

Fair and swift peer-review system

Efficient typesetting and proofreading procedure

Display of the result of downloads and visits, as well as the number of cited articles

Maximum dissemination of your research work

Submit your manuscript at: http://papersubmission.scirp.org/

Or contact ojcd@scirp.org 